\title{
A framework for modeling uncertainty in regional climate change
}

\author{
Erwan Monier • Xiang Gao $\cdot$ Jeffery R. Scott • \\ Andrei P. Sokolov • C. Adam Schlosser
}

Received: 30 January 2013 / Accepted: 9 March 2014 / Published online: 6 June 2014

(C) Springer Science+Business Media Dordrecht 2014

\begin{abstract}
In this study, we present a new modeling framework and a large ensemble of climate projections to investigate the uncertainty in regional climate change over the United States (US) associated with four dimensions of uncertainty. The sources of uncertainty considered in this framework are the emissions projections, global climate system parameters, natural variability and model structural uncertainty. The modeling framework revolves around the Massachusetts Institute of Technology (MIT) Integrated Global System Model (IGSM), an integrated assessment model with an Earth System Model of Intermediate Complexity (EMIC) (with a two-dimensional zonal-mean atmosphere). Regional climate change over the US is obtained through a two-pronged approach. First, we use the IGSMCAM framework, which links the IGSM to the National Center for Atmospheric Research (NCAR) Community Atmosphere Model (CAM). Second, we use a pattern-scaling method that extends the IGSM zonal mean based on climate change patterns from various climate models. Results show that the range of annual mean temperature changes are mainly driven by policy choices and the range of climate sensitivity considered. Meanwhile, the four sources of uncertainty contribute more equally to end-of-century precipitation changes, with natural variability dominating until 2050 . For the set of scenarios used in this study, the choice of policy is the largest driver of uncertainty, defined as the range of warming and changes in precipitation, in future projections of climate change over the US.
\end{abstract}

This article is part of a Special Issue on "A Multi-Model Framework to Achieve Consistent Evaluation of Climate Change Impacts in the United States" edited by Jeremy Martinich, John Reilly, Stephanie Waldhoff, Marcus Sarofim, and James McFarland.

Electronic supplementary material The online version of this article (doi:10.1007/s10584-014-1112-5) contains supplementary material, which is available to authorized users.

E. Monier $(\bowtie) \cdot$ X. Gao · J. R. Scott · A. P. Sokolov · C. A. Schlosser Joint Program on the Science and Policy of Global Change, Massachusetts Institute of Technology, Cambridge, Massachusetts, USA

e-mail: emonier@mit.edu 


\section{Introduction}

It is well established that the uncertainty in climate system parameters and projected emissions are important drivers of uncertainty in global climate change (Sokolov et al. 2009; Webster et al. 2012). In our modeling system, the climate response to given emissions is essentially controlled by three climate parameters, i.e., the climate sensitivity, the strength of aerosol forcing and the ocean heat uptake rate (Forest et al. 2001, 2008). Future emissions are driven by future economic activity and technological pathways influenced by climate policies, and population growth. Other sources of uncertainty in future climate projections, in particular at the regional level, include natural variability and structural uncertainty associated with differences in parameterization in existing climate models. It is well known that year-to-year variability in the climate system is large, in particular at high latitudes, making the emergence of significant climate change slow and signal-to-noise detection difficult (Mahlstein et al. 2011, 2012; Hawkins and Sutton 2012). At the same time, climate projections are heavily influenced by the characteristics of the chosen climate model and global climate models remain inconsistent in capturing regional precipitation changes and other atmospheric processes. Quantifying the likelihood of future regional climate change, such as the potential range of future warming, might be insightful to policy makers and impact modeling research groups who investigate climate change and its societal impacts at the regional level, including agriculture productivity, water resources and energy demand (Reilly et al. 2013).

In this study, we introduce a new modeling framework to investigate the uncertainty in regional climate change over the United States (US) associated with four sources of uncertainty, namely: (i) uncertainty in the emissions projections; (ii) uncertainty in the response of the global climate system to changes in greenhouse gases and aerosols concentrations; (iii) natural variability; and (iv) model structural uncertainty. The modeling framework is built around the Massachusetts Institute of Technology (MIT) Integrated Global System Model (IGSM) (Sokolov et al. 2005, 2009), an integrated assessment model with an Earth System Model of Intermediate Complexity (EMIC) (with a twodimensional zonal-mean atmosphere). Regional climate change over the US is obtained through a two-pronged approach. First, we use the IGSM-CAM framework, which links the IGSM to the National Center for Atmospheric Research (NCAR) Community Atmosphere Model (CAM) (Monier et al. 2013a). Secondly, we use a pattern-scaling method that extends the IGSM zonal mean based on climate change patterns from various climate models (Schlosser et al. 2013). This two-pronged approach has been used to compute probabilistic projections of 21 st century climate change over Northern Eurasia (Monier et al. 2013b).

In this paper, we present a description of the framework for modeling uncertainty in regional climate change. We then give a description of the matrix of simulations and present results of regional climate change over the US. We place a particular emphasis on quantifying the range of uncertainty and identifying the contributions of different sources of uncertainty considered in this study. The simulations presented here are part of a multi-model project to achieve consistent evaluation of climate change impacts in the US (Waldhoff et al. 2013). 


\section{Methodology}

\subsection{Modeling framework}

In this study, the core simulations use the MIT IGSM version 2.3 (Dutkiewicz et al. 2005; Sokolov et al. 2005), an integrated assessment model that couples an Earth System Model of Intermediate Complexity (EMIC), with a two-dimensional zonal-mean atmosphere, to a human activity model. The IGSM includes a representation of terrestrial water, energy, and ecosystem processes, global scale and urban chemistry including 33 chemical species, carbon and nitrogen cycle, thermodynamical sea ice, and a three-dimensional dynamical ocean component based on the MIT ocean general circulation model (Marshall et al. 1997a, b). Finally, the human systems component of the IGSM is the MIT Emissions Predictions and Policy Analysis (EPPA) model (Paltsev et al. 2005), which provides projections of world economic development and emissions over 16 global regions along with an analysis of proposed emissions control measures.

Since the IGSM atmospheric component is two-dimensional (zonally averaged), heat and freshwater fluxes are anomaly coupled in order to simulate a realistic ocean state. In order to more realistically capture surface wind forcing over the ocean, six-hourly National Centers for Environmental Prediction (NCEP) reanalysis 1 (Kalnay et al. 1996) surface 10meter wind speed from 1948-2007 is used to formulate wind stress. The data are detrended through the analysis of the changes in zonal mean over the ocean (by month) across the full 60-year period; this has little impact except over the Southern Ocean, where the trend is quite significant (Thompson and Solomon 2002). For any given model calendar year, a random calendar year of wind stress data is applied to the ocean. This approach ensures that both short-term and interannual variability are represented in the ocean's surface forcing. Different random sampling can be applied to simulate different natural variability, augmenting the traditional approach of specifying perturbations in initial conditions.

Because the IGSM includes a human activity model, it is possible to analyze uncertainties in emissions resulting from both uncertainty in model parameters and uncertainty in future climate policy decisions. Another major feature is the flexibility to vary key climate parameters controlling the climate response: climate sensitivity, strength of the aerosol forcing and ocean heat uptake rate. Because the IGSM has a two-dimensional zonal mean atmosphere, it cannot be directly used to simulate regional climate change. To simulate climate change over the US, we use a two-pronged method.

On the one hand, the MIT IGSM-CAM framework (Monier et al. 2013a) links the IGSM to the National Center for Atmospheric Research (NCAR) Community Atmosphere Model (CAM) version 3.1 (Collins et al. 2006b), with new modules developed and implemented in CAM to allow climate parameters to be changed to match those of the IGSM. In particular, the climate sensitivity of CAM is changed using a cloud radiative adjustment method (Sokolov and Monier 2012). In the IGSM-CAM framework, CAM is driven by greenhouse gas concentrations and aerosol loading computed by the IGSM model as well as IGSM sea surface temperature (SST) anomalies from a control simulation corresponding to pre-industrial forcing superposed on an observed monthly climatology from the merged Hadley-OI SST, a surface boundary dataset designed for uncoupled simulations with CAM (Hurrell et al. 2008). More details on the IGSM-CAM framework can be found in Monier et al. (2013a). 
On the other hand, a pattern scaling method (Schlosser et al. 2013) extends the latitudinal projections of the IGSM 2D zonal-mean atmosphere by applying longitudinally resolved patterns from observations and from climate-model projections archived from exercises carried out for the Fourth Assessment Report (AR4) of the Intergovernmental Panel on Climate Change (IPCC) (Meehl et al. 2007). The pattern scaling method relies on transformation coefficients that reflect the relative value of any given variable at a specific grid cell in relation to its zonal mean. These transformation coefficients are calculated for each month of the year. The following scheme is applied to expand IGSM zonal mean variables across the longitude:

$$
\begin{gathered}
V_{x, y}^{I G S M}=\left(C_{x, y}^{O B S}+\frac{d C_{x, y}^{A R 4}}{d T_{G l o b a l}} \cdot \Delta T_{G l o b a l}\right) \cdot V_{y}^{I G S M} \\
C_{x, y}^{O b s / A R 4}=\frac{V_{x, y}^{O b s / A R 4}}{V_{y}^{O b s / A R 4}}
\end{gathered}
$$

where $\mathrm{x}$ and $\mathrm{y}$ are the longitude and latitude of a grid cell, $V_{y}^{I G S M}$ and $V_{x, y}^{I G S M}$ are the original zonal mean IGSM data and the transformed IGSM data, $\Delta T_{G l o b a l}$ is the global IGSM temperature changes from present-day. $C_{x, y}^{O B S}$ are the transformation coefficients for present-day and $\frac{d C_{x, y}^{A R 4}}{d T_{G l o b a l}}$ are the rates of change of the transformation coefficient from IPCC AR4 models with respect to global temperature change. The pattern scaling method is applied to surface air temperature, precipitation, surface wind speed, surface relative humidity, total cloud cover, sea surface temperature and surface water vapor pressure. $C_{x, y}^{O B S}$ are calculated for present-day conditions (for the period 1980-2009) using the Modern Era Retrospective-analysis for Research and Applications (MERRA, Rienecker et al. 2011) for all variables except for precipitation, which relies on the Global Precipitation Climatology Project (GPCP, Adler et al. 2003). GPCP is preferred over MERRA for precipitation because of the presence of substantial biases and discontinuity in the MERRA precipitation over the 1980-2009 period (Kennedy et al. 2011; Rienecker et al. 2011). Finally, $\frac{d C_{x, y}^{A R 4}}{d T_{\text {Global }}}$ are calculated based on the difference in 10-year mean climatology of $C_{x, y}^{A R 4}$ between present-day conditions and the time of doubling of $\mathrm{CO}_{2}$ in the IPCC simulations with a $1 \%$ per year increase in $\mathrm{CO}_{2}$ (equivalent to year 70 of the simulation), divided by the global mean temperature difference of the same time period. The estimates of the derivatives are not very sensitive to the choice of the averaging period or of the scenario considered. More details on the pattern scaling method can be found in Schlosser et al. (2013). This method allows us to separate the difference in regional patterns of change between models from the global climate system response.

The IGSM-CAM simulations provide daily output at a resolution of $2^{\circ} \times 2.5^{\circ}$ while the IGSM-pattern scaling method provides monthly output at the same $2^{\circ} \times 2.5^{\circ}$ horizontal resolution.

\subsection{Description of the simulations}

To investigate the uncertainty in projections of future climate change, a core of 12 simulations with the IGSM is conducted with four values of climate sensitivity and three emissions scenarios. The three emissions scenarios are (i) a reference scenario with unconstrained emissions after 2012 (REF), with a total radiative forcing of $10.0 \mathrm{~W} \mathrm{~m}^{-2}$ by 2100 ; (ii) a stabilization scenario (POL4.5), with a total radiative forcing of $4.5 \mathrm{~W} \mathrm{~m}^{-2}$ by 2100 ; and (iii) a 
more stringent stabilization scenario (POL3.7), with a total radiative forcing of $3.7 \mathrm{~W} \mathrm{~m}^{-2}$ by 2100 . More details on the emissions scenarios and economic implications, along with how they relate to the Representative Concentration Pathway (RCP) scenarios are given in Paltsev et al. (2013). To limit the number of simulations in this study we only consider one version of the three-dimensional dynamical ocean, with one particular ocean heat uptake rate (see Monier et al. 2013a). The four values of climate sensitivity (CS) considered are 2.0, 3.0, 4.5 and $6.0^{\circ} \mathrm{C}$, which represent respectively the lower bound (CS2.0), best estimate (CS3.0) and upper bound (CS4.5) of climate sensitivity based on the Fourth Assessment Report of the Intergovernmental Panel on Climate Change (Pachauri and Reisinger 2007), and a low probability/high risk climate sensitivity (CS6.0). Because the correlation between net aerosol forcing and climate sensitivity are conditional on the ocean heat uptake rate, we rely on the bivariate (climate sensitivity-net aerosol forcing) probability distribution for the particular value of ocean heat uptake rate used in this study to estimate the net aerosol forcing that provides the best agreement to reproduce historical climate change (Monier et al. 2013a). The values for the net aerosol forcing are $-0.25 \mathrm{~W} / \mathrm{m}^{2},-0.70 \mathrm{~W} / \mathrm{m}^{2}$, $-0.85 \mathrm{~W} / \mathrm{m}^{2}$ and $-0.95 \mathrm{~W} / \mathrm{m}^{2}$ respectively, for $\mathrm{CS}=2.0^{\circ} \mathrm{C}, \mathrm{CS}=3.0^{\circ} \mathrm{C}, \mathrm{CS}=4.5^{\circ} \mathrm{C}$ and $\mathrm{CS}=6.0^{\circ} \mathrm{C}$.

For each set of emissions scenario and climate sensitivity, a five-member ensemble of IGSM-CAM simulations is run with different random wind sampling and initial conditions, referred to as simply initial conditions in the remainder of the article, in order to account for the uncertainty in natural variability (Monier et al. 2013a), and the IGSM-pattern scaling is applied to four different patterns of regional climate change. Three IPCC AR4 climate models are chosen along with the IPCC AR4 multi-model ensemble mean. First, the NCAR Community Climate System Model version 3 (CCSM3.0) (Collins et al. 2006a) is chosen to compare with the IGSM-CAM results since both modeling systems have the same atmospheric and land components and they show similar biases over land (Monier et al. 2013a). However, because they have different ocean component, simulations with the IGSM-CAM and the IGSM-pattern scaling with CCSM3.0 are not necessarily expected to be identical. Nonetheless, this provides an opportunity to examine if the relative simple pattern-scaling scheme is sufficiently effective to replicate what can be represented in a more sophisticated three-dimensional climate model. The two additional models chosen are the models with the largest and smallest projected increases in precipitation over the US, respectively, the Bjerknes Centre for Climate Research Bergen Climate Model version 2.0 (BBCR_BCM2.0, Otterâ et al. 2009) and the Model for Interdisciplinary Research on Climate version 3.2 medium resolution (MIROC3.2_medres, Hasumi and Emori 2004). Finally, the multi-model ensemble pattern of regional climate change is obtained from 17 IPCC AR4 climate models (see Schlosser et al. 2013).

Overall, the modeling framework and experimental design used in this study allow us to investigate the uncertainty in regional climate change associated with four dimensions of uncertainty: emissions projections, global climate system parameters, natural variability and structural uncertainty. A summary of the simulation matrix is shown in Fig. 1.

\section{Results}

In the remainder of this article, we refer to present-day as the mean over the 1991-2010 period and to 2100 as the mean over the 2091-2110 period. 


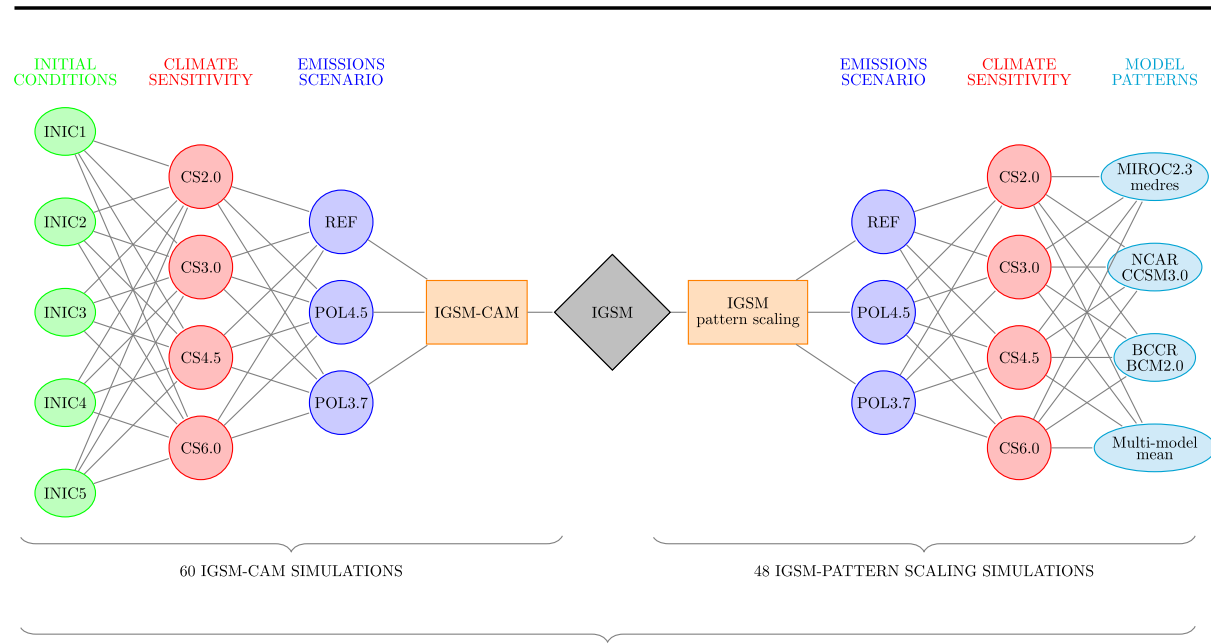

TOTAL OF 108 SIMULATIONS

Fig. 1 Summary of the experimental design of the modeling framework and the simulation matrix used in this study

\subsection{Time series of US mean temperature and precipitation}

Figure 2 shows time series of US mean surface air temperature and precipitation anomalies from present-day for all the simulations with the IGSM-CAM, their ensemble mean and the IGSM-pattern scaling along with observations. The simulations in this study exhibit a wide range of changes by the end of the century relative to present-day. The projected warming ranges from less than $1.0{ }^{\circ} \mathrm{C}$ to about $10{ }^{\circ} \mathrm{C}$ while the changes in precipitation range from a decrease of $-0.1 \mathrm{~mm} /$ day to increases up to $0.7 \mathrm{~mm} /$ day. The largest changes generally occur for the reference emissions scenario and for the highest climate sensitivity. The IGSM-CAM simulations display a strong interannual variability, especially for precipitation, which is in very good agreement with the observations over the historical period. As a result, comparing two particular simulations to identify the impact of, for example, the implementation of a stabilization policy or different values of climate sensitivity, is generally difficult. However, once the five-member ensemble is averaged, the signal is more easily extracted from the noise. Meanwhile, simulations with the IGSMpattern scaling method show limited interannual variability, even less than the IGSM-CAM ensemble means simulations. This is because the temporal variability in temperature and precipitation in the IGSM-pattern scaling method is controlled entirely by the IGSM zonal mean, which displays a much weaker variability than would any particular grid cell along the same latitude. For this reason, the IGSM-pattern scaling method underestimates natural variability and its potential changes, as well as climate and weather extreme events. Finally, the choice of the model for the pattern scaling method has limited impact on the US mean surface air temperature changes. However, the pattern scaling method projects both increases and decreases in the US mean precipitation. This reflects the large uncertainty in projections of precipitation, in particular over the US, by the IPCC AR4 models (Randall et al. 2007) and the strength of the IGSM-pattern scaling method in accounting for structural uncertainty. 
a

U.S. SURFACE AIR TEMPERATURE ANOMALY ( $\left.{ }^{\circ} \mathrm{C}\right)($ Base: 1991-2010) IGSM-CAM INDIVIDUAL SIMULATIONS

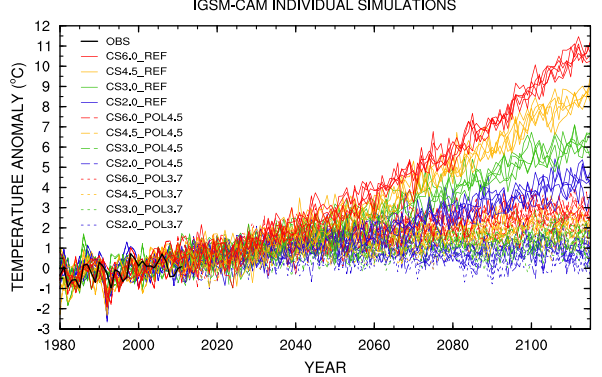

IGSM-CAM ENSEMBLE MEANS
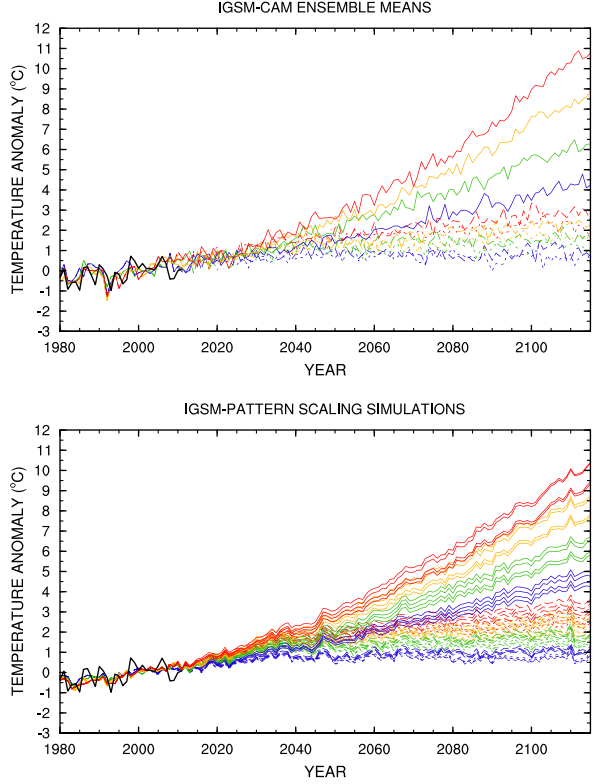

b
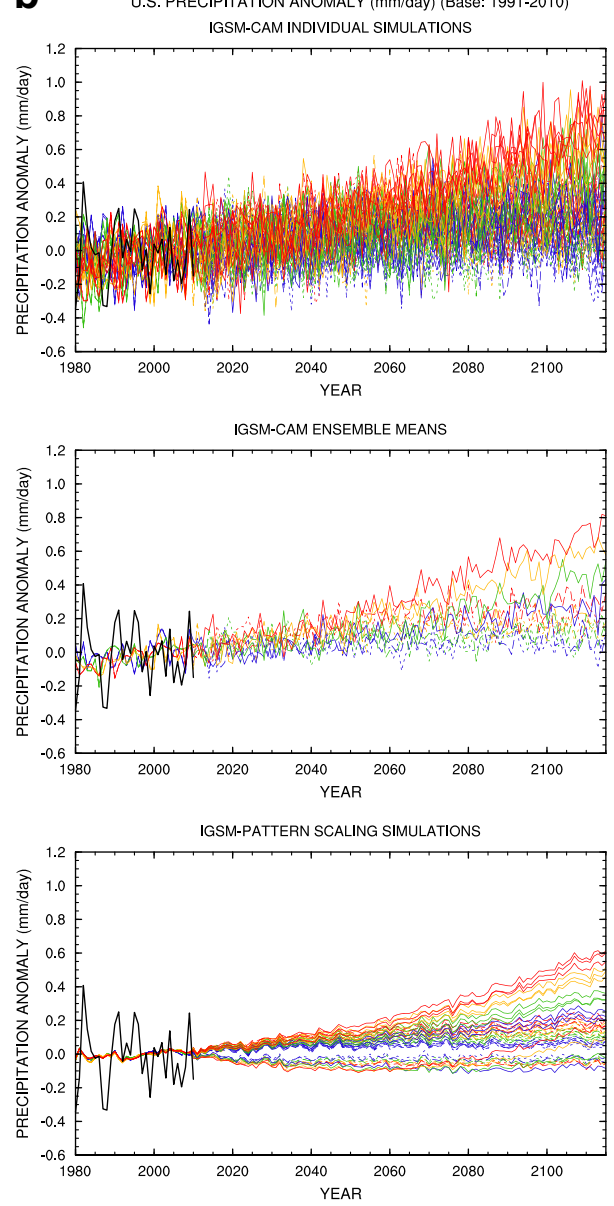

Fig. 2 Time series of US mean (a) surface air temperature and (b) precipitation anomalies from present-day (1991-2010 mean) for all the simulations with the IGSM-CAM, their ensemble means and the IGSM-pattern scaling along with observations. The black lines represent observations, the Goddard Institute for Space Studies (GISS) surface temperature (GISTEMP, Hansen et al. 2010) and the 20th Century Reanalysis V2 precipitation (Compo et al. 2011). The blue, green, orange and red lines represent, respectively, the simulations with a climate sensitivity of $2.0,3.0,4.5$ and $6.0^{\circ} \mathrm{C}$. The solid, dashed and dotted lines represent, respectively, the simulations with the reference scenario, stabilization scenario at $4.5 \mathrm{~W} / \mathrm{m}^{2}$ and the stabilization scenario at $3.7 \mathrm{~W} / \mathrm{m}^{2}$

\subsection{Regional patterns of change}

Figure 3 shows maps of changes in surface air temperature in 2100 relative to present-day for the IGSM-CAM and IGSM-pattern scaling simulations, for different initial conditions and different models under the POL4.5_CS3.0 scenario, for different values of climate sensitivity under the POL4.5 scenario, and for different emissions scenarios for CS3.0. The same analysis but focusing on the REF scenario is shown in Online Resource 2. Overall, Fig. 3 displays a wide range of warming amongst the simulations presented in this study. The IGSM-CAM simulations with different initial conditions under the same CS3.0_POL4.5 
a

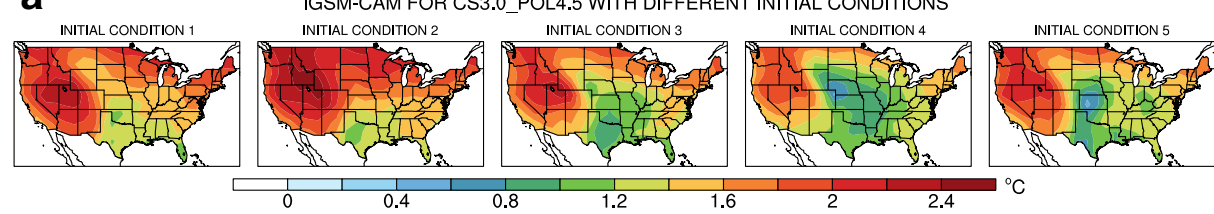

b IGSM-CAM ENSEMBLE MEAN FOR POL4.5 WITH DIFFERENT CLIMATE SENSITIVITIES

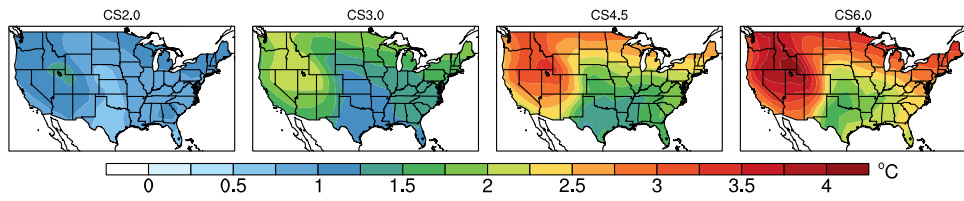

C IGSM-CAM ENSEMBLE MEAN FOR CS3.0 WITH DIFFERENT POLICIES

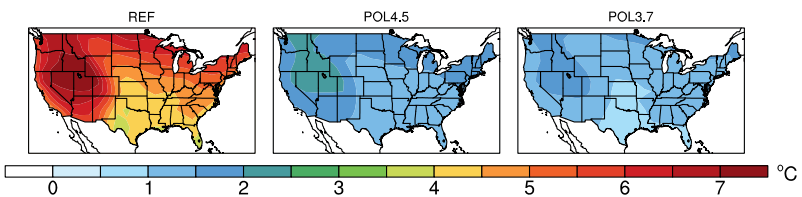

d IGSM-PATTERN SCALING FOR C3.0_POL4.5 WITH DIFFERENT MODELS

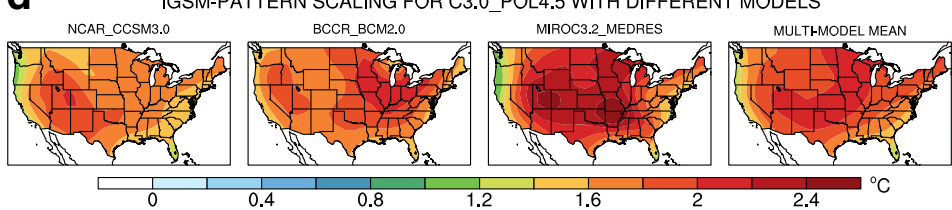

Fig. 3 Changes in surface air temperature (in ${ }^{\circ} \mathrm{C}$ ) in 2100 (2091-2110 mean) relative to present-day (19912010 mean) for (a) the IGSM-CAM simulations with different initial conditions under the POL4.5_CS3.0 scenario, $\mathbf{b}$ the IGSM-CAM ensemble means with different climate sensitivities under the POL4.5 scenario, c the IGSM-CAM ensemble means with different emissions scenarios under the CS3.0 scenario and (d) the IGSM-pattern scaling with different climate models under the POL4.5_CS3.0 scenario

scenario show similar patterns of temperature change. The largest warming takes place over the Great Basin while the South Central States show the least amount of warming. Differences between the five initial conditions are less than $1.0^{\circ} \mathrm{C}$, largely due to the use of 20-year averages in this analysis. The IGSM-CAM ensemble means for the POL4.5 emissions scenario with different values of climate sensitivity show a wide range in the magnitude of the warming. The largest warming is seen for the ensemble mean with the highest climate sensitivity, where increases in temperature over the Great Basin reach up to $4.0^{\circ} \mathrm{C}$ under the POL4.5 scenario (and up to $12.0^{\circ} \mathrm{C}$ under the REF scenario). On the other hand, the warming is reduced to just $1^{\circ} \mathrm{C}$ in the ensemble mean with the lowest value of climate sensitivity under the POL4.5 scenario (and to $5^{\circ} \mathrm{C}$ under the REF scenario). The differences in warming due to the implementation of different emissions scenarios under the same climate sensitivity (CS3.0) can also be seen in Fig. 3. It shows that both stabilization policies greatly reduce the warming, with increases in temperature less than $2.5^{\circ} \mathrm{C}$ over the entire US. Finally, the IGSM-pattern scaling shows that the location and magnitude of the largest warming differs significantly between the different models. 

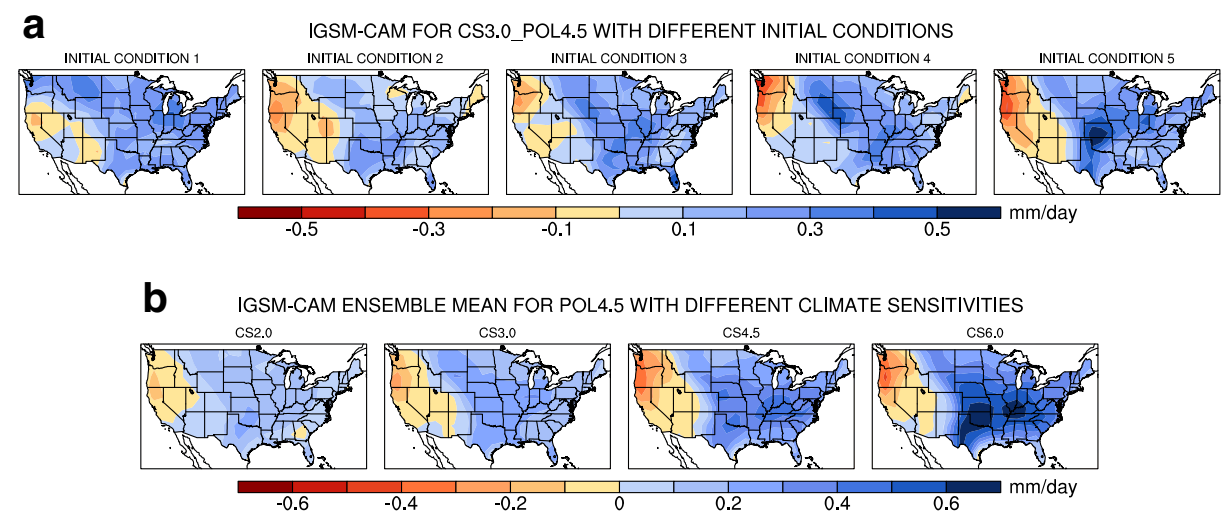

C IGSM-CAM ENSEMBLE MEAN FOR CS3.0 WITH DIFFERENT POLICIES
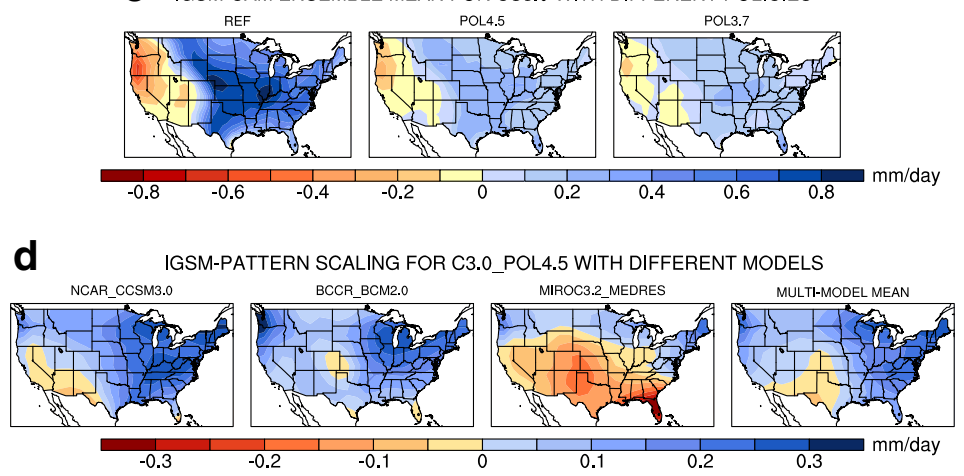

Fig. 4 Same as Fig. 3 for precipitation changes (in $\mathrm{mm} /$ day)

The same analysis as Fig. 3 for changes in precipitation is shown in Fig. 4, while the analysis focusing on the REF scenario is shown in Online Resource 3. The IGSM-CAM generally shows decreases in precipitation on the West coast and increases everywhere else. The use of different initial conditions leads to distinctively different locations and magnitudes of maximum changes in precipitation, and to different extent of the regions of drying. For example, the largest decrease in precipitation, reaching up to $0.5 \mathrm{~mm} /$ day, takes place in the simulation with initial condition 4 but is mostly constrained to Oregon and Washington. On the other hand, the simulation with initial condition 2 projects precipitation decreases of smaller magnitude (less than $0.3 \mathrm{~mm} /$ day) but over a larger region, including parts of New England. Furthermore, the range of precipitation changes between IGSM-CAM simulations with different initial conditions appears as large as the range between ensemble simulations with different values of climate sensitivity. This underlines the fact that initial conditions have a larger impact on regional precipitation changes than on temperature. The impact of the climate sensitivity appears to be strongly localized. The greater the climate sensitivity the larger is the increase in precipitation over the Great Plains. On the other hand, the implementation of a stabilization policy leads to decreases in the magnitude of precipitation changes over the entire US. Finally, Fig. 4 shows the difference in the patterns of precipitation changes for the IGSM-pattern scaling. CCSM3.0 simulates decreases in precipitation over California, Arizona, most of New Mexico and the western part of Nevada, 

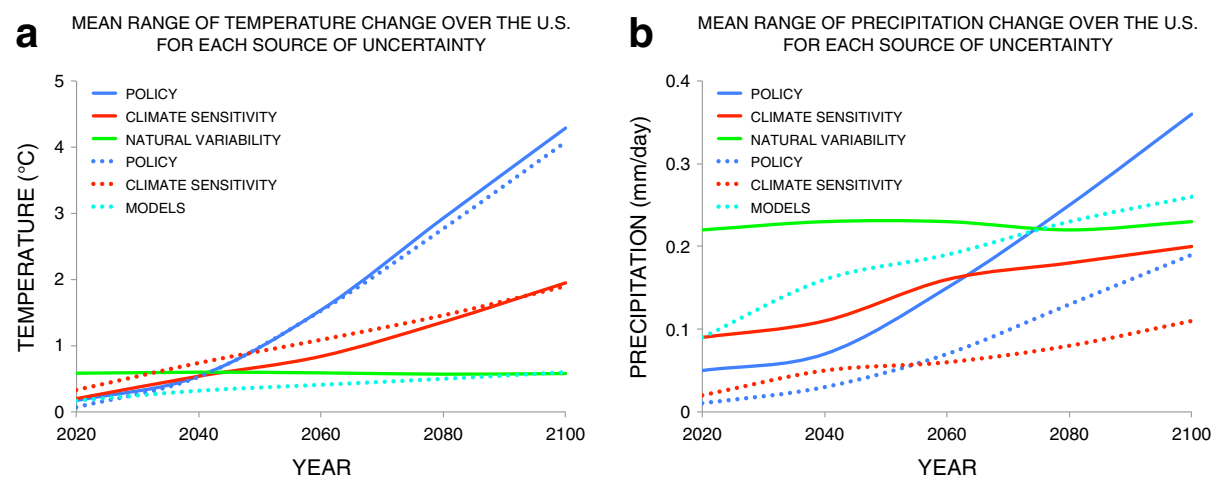

Fig. 5 Times series of the mean (area-averaged over the contiguous United States) range of changes in (a) temperature $\left({ }^{\circ} \mathrm{C}\right.$ ) and (b) precipitation (mm/day) relative to present-day (1991-2010 mean) for each source of uncertainty (policy, climate sensitivity, natural variability and model) for the IGSM-CAM ensemble and the IGSM-pattern scaling ensemble. The range is calculated every 20 years $(2020,2040,2060,2080$ and 2100) based on the 20-year mean centered on the year considered

and increases everywhere else. This pattern bears some resemblance with the pattern of precipitation of the IGSM-CAM, except that the latter extends more along the north of the Pacific coast. BCCR_BCM2.0 displays increases in precipitation over most of the US. MIROC3.2_MEDRES shows moistening over the Northern US and drying over the Southern US. Finally, the multi-model mean displays decreases in precipitation over the Western Texas, most of New Mexico and parts of Colorado, Kansas and Arizona.

Figure 5 shows times series of the mean (area-averaged over the contiguous US) range of temperature and precipitation changes from present-day for each source of uncertainty in the IGSM-CAM ensemble and in the IGSM-pattern scaling ensemble. The method to compute the range of temperature and precipitation changes for each source of uncertainty and ensemble is provided in Online Resource 4. In this analysis, we do not consider the $6{ }^{\circ} \mathrm{C}$ climate sensitivity scenario, which has a low probability, in order to account for a more probable range of climate sensitivity. This analysis reveals that the contribution from each source of uncertainty changes in time and that they contribute differently to temperature and precipitation changes. For changes in temperature, the two ensembles show very similar contributions of the choice of policy and the climate sensitivity, both increasing in time and following the same trajectory and magnitude. The analysis shows that natural variability is the largest source of uncertainty at the beginning of the century (before 2020) and that after 2060, the choice of policy dominates. Meanwhile, the climate sensitivity is the second largest source of uncertainty over most of the century. By 2100, the range of temperature changes caused by differences in policy is more than twice as large as the range associated with the climate sensitivity. Finally, the choice of model shows the least contribution to the overall range of temperature changes over the US. For precipitation changes, the contribution of the different sources of uncertainty is very different than for temperature changes. In particular, the two ensembles show substantial discrepancies in the estimates of the contribution of the choice of policy and climate sensitivity (more details can be found in Online Resource 4). These differences can be explained by the contamination of natural variability in the IGSM-CAM ensemble since averaging over 5 initial conditions is not enough to completely filter out natural variability. Additionally, the pattern scaling method cannot represent the potential impacts of climate sensitivity or policy on precipitation at the local level, 
a

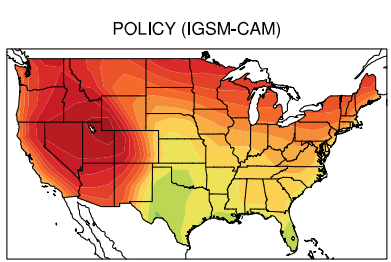

POLICY (PATTERN SCALING)

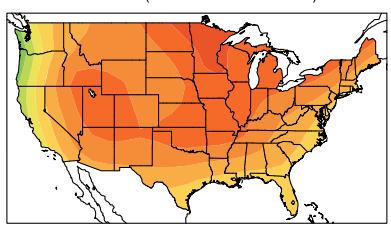

CLIMATE SENSITIVITY (IGSM-CAM)

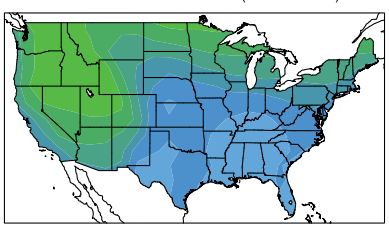

CLIMATE SENSITIVITY (PATTERN SCALING)

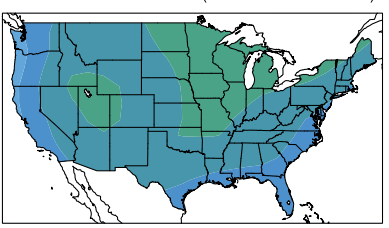

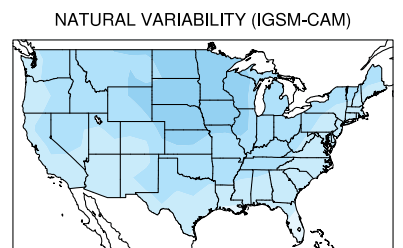

MODEL (PATTERN SCALING)

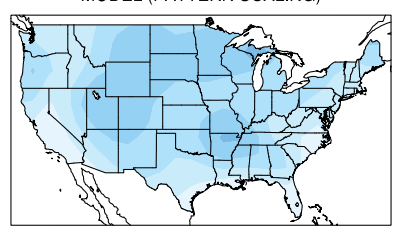

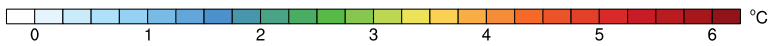

b MEAN RANGE OF PRECIPITATION CHANGE FOR EACH SOURCE OF UNCERTAINTY

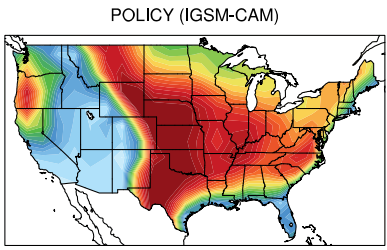

POLICY (PATTERN SCALING)

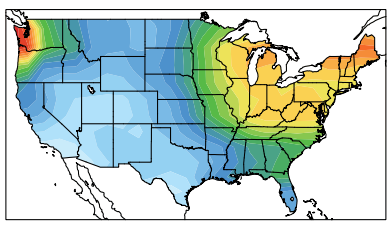

CLIMATE SENSITIVITY (IGSM-CAM)

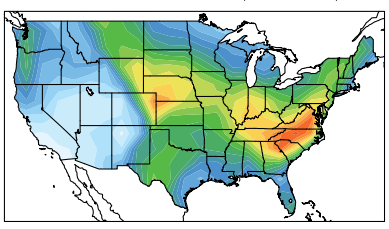

CLIMATE SENSITIVITY (PATTERN SCALING)

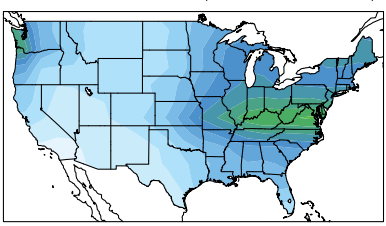

NATURAL VARIABILITY (IGSM-CAM)

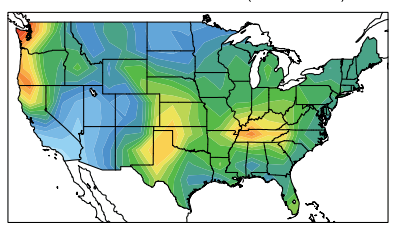

MODEL (PATTERN SCALING)

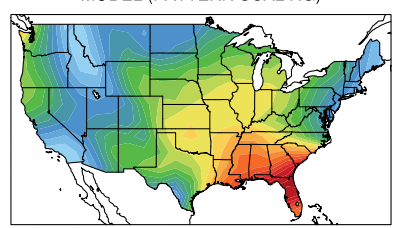

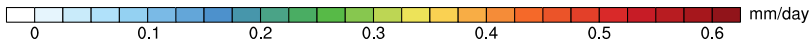

Fig. 6 Maps of the range of changes in (a) temperature $\left({ }^{\circ} \mathrm{C}\right)$ and (b) precipitation (mm/day) in 2100 (2091-2110 mean) relative to present-day (1991-2010 mean) for each source of uncertainty (policy, climate sensitivity, natural variability and model) for the IGSM-CAM ensemble and the IGSM-pattern scaling ensemble

such as changes in circulation patterns leading to different location and magnitude of precipitation. For this reason, the IGSM-CAM and the IGSM-pattern scaling ensembles likely overestimates and underestimate, respectively, the contributions of the choice of policy and climate sensitivity. Nonetheless, this analysis reveals the large role of natural variability in precipitation changes, being the largest source of uncertainty until 2060. By the end of the century, the four sources of uncertainty seem to contribute more equally. It demonstrates the importance of considering multiple sources of uncertainty in future regional climate projections of precipitation changes.

Finally, Fig. 6 shows the spatial distribution of the range of temperature and precipitation changes in 2100 relative to present-day for each source of uncertainty considered 
in this study and for each ensemble. The contributions of the choice of policy and climate sensitivity display patterns similar to the IGSM-CAM (in the IGSM-CAM ensemble) and to the multi-model mean (in the IGSM-pattern scaling ensemble). This indicates that changing the policy or the climate sensitivity essentially scales the temperature changes. Meanwhile the contributions of natural variability and of the choice of model display little spatial heterogeneity and very small magnitudes (less than $1.0^{\circ} \mathrm{C}$ over the entire US). For precipitation, the range of changes for each source of uncertainty is more heterogeneous than for temperature. At the same time, the contributions of the choice of policy and climate sensitivity display patterns corresponding to the distribution of the largest changes in precipitation, regardless of the sign of these changes, in the IGSM-CAM and in the multimodel mean, just like for temperature. While the analysis of each ensemble does not show perfect agreement, it reveals two hot spot regions that seem particularly affected by the choice of policy and climate sensitivity: the Pacific Northwest and the Northeastern US. The large range of precipitation changes in the Central US displayed in the IGSM-CAM ensemble (the main difference from the IGSM-pattern scaling ensemble) is likely due to the contamination of natural variability previously discussed. The role of natural variability and the choice of model display similar spatial distributions, with the largest contributions in the Pacific Northwest and the Southern US. In addition, the models considered in this study tend to disagree the most over the Southeastern US. This analysis demonstrates that the range of precipitation changes associated with each source of uncertainty generally displays different spatial distribution and different magnitude. Finally, a noticeable feature is the small range over the southwest region covering southern California, Arizona, Utah and southern Nevada in all sources of uncertainty, indicating that this region shows the least amount of uncertainty in precipitation changes. This is likely because that region also displays the least amount of absolute precipitation and thus displays little absolute changes in precipitation.

\section{Summary and Conclusion}

As part of a multi-model project to achieve consistent evaluation of climate change impacts in the US (Waldhoff et al. 2013), we use a series of 12 core simulations with the MIT IGSM with three different emissions scenarios and four values of climate sensitivity (Paltsev et al. 2013). We obtain regional climate change over the US using a two-pronged approach. On the one hand, we use the MIT IGSM-CAM framework, which links the IGSM to the CAM model, and run each of the 12 core simulations with five different initial conditions to account for uncertainty in natural variability. On the other hand, we apply a pattern scaling method to extend the latitudinal projections of the IGSM 2D zonal-mean atmosphere by applying longitudinally resolved patterns from 3 IPCC AR4 climate models and the multi-model mean based on 17 IPCC AR4 models. The three models chosen are the NCAR_CCSM3.0, which shares the same atmospheric model as the IGSM-CAM, BCCR_BCM2.0, which projects the largest increases in precipitation over the US, and MIROC3.2_medres, which predicts the least amount of precipitation increases over the US. This new framework for modeling uncertainty in regional climate change covers four dimensions of uncertainty: projected emissions, the global climate system response to changes in greenhouse gases and aerosols concentrations, natural variability and model structural uncertainty. Altogether, these simulations provide an efficient matrix of future climate projections to study climate impacts under uncertainty. 
The simulations display a large range of US mean temperature and precipitation changes, and different regional patterns of change. In addition, the two different methods have very different treatments of natural variability. The IGSM-CAM physically simulates changes in both mean climate and extreme events (Monier and Gao 2014), but relies on one particular model. The pattern scaling approach allows the spatial patterns of regional climate change of different climate models to be considered, but significantly underestimates yearto-year variability and cannot simulate extreme events or their potential changes under climate change. Together, these two methods provide complementary skills and an efficient framework to investigate uncertainty in future projections of regional climate change. The limitations of each methodology should be carefully accounted for when using this framework to drive impact models. In particular, researchers using climate simulations to drive impact models should always use individual model simulations and not ensemble mean simulations in order to account for natural variability. That is because natural variability is a driver for extreme climate and weather events, which can dominate impacts, and would not be accounted in ensemble mean simulations, as illustrated in Mills et al. (2014).

Finally, an analysis of the contribution of the four different sources of uncertainty reveals that the choice of policy and the value of the climate sensitivity have the largest impact on surface air temperature changes (the choice of policy being the dominant contributor), while the contributions from natural variability and structural uncertainty are small. On the other hand, the contributions of the four sources of uncertainty are more equal for changes in precipitation over the US but show large spatial heterogeneity. The role of natural variability on precipitation changes is substantial, in particular until 2050 when it dominates. This result is consistent with previous studies highlighting the important role of natural variability on regional climate projections (Deser et al. 2012; Monier et al. 2013a, b). Between 2050 and 2080, the four sources of uncertainty contribute equally to changes in precipitation over the US. After that, the choice of policy dominates similarly to previous studies (Hawkins and Sutton 2009, 2011). Since the pattern scaling method is based on a single realization of a climate model, the differences between models likely include contribution from natural variability associated with using different initial conditions. This is supported by the work of Deser et al. (2014) and reinforces the important role that natural variability plays in regional climate projections.

In light of these new results, it appears clear that the largest source of uncertainty in endof-the-century projections of climate change over the US is also the only source that society has a control over: the emissions scenario. This should reflect the need to seriously consider implementing a global climate policy aiming at stabilizing greenhouse gases concentrations in the atmosphere.

While this study considers major sources of uncertainty in regional climate projections, it does not consider all possible sources. For example, Li et al. (2012) investigate the uncertainty in high-resolution temperature scenarios for North America from dynamical downscaling using different regional climate models and statistical downscaling. In addition, the contribution of each source of uncertainty depends strongly on the particular samples and choices made in this study. The implementation of only moderate policies or the choice of only low values of climate sensitivity would certainly decrease the estimates of their contribution to the overall changes. It should be reemphasized that we exclude the $6{ }^{\circ} \mathrm{C}$ climate sensitivity scenario, because of its low probability, when estimating the range of temperature and precipitation changes for each source of uncertainty considered in this study. In addition, sampling the ocean heat uptake rate would likely change the regional projections and the estimates of the impact of the uncertainty in the global climate 
response on changes in temperature and precipitation over the US. Nonetheless, this analysis demonstrates the relevance of modeling each source of uncertainty. It further demonstrates the need of new and more complete frameworks for modeling uncertainty in regional climate change.

Acknowledgments This work was partially funded by the US Environmental Protection Agencys Climate Change Division, under Cooperative Agreement XA-83600001 and by the US Department of Energy, Office of Biological and Environmental Research, under grant DEFG02- 94ER61937. The Joint Program on the Science and Policy of Global Change is funded by a number of federal agencies and a consortium of 40 industrial and foundation sponsors. (For the complete list see http://globalchange.mit.edu/sponsors/all). This research used the Evergreen computing cluster at the Pacific Northwest National Laboratory. Evergreen is supported by the Office of Science of the US Department of Energy under Contract No. (DE-AC0576RL01830). 20th Century Reanalysis V2 data provided by the NOAA/OAR/ESRL PSD, Boulder, Colorado, USA, from their Web site at http://www.esrl.noaa.gov/psd/.

\section{References}

Adler R, Huffman G, Chang A, Ferraro R, Xie P, Janowiak J, Rudolf B, Schneider U, Curtis S, Bolvin D, et al. (2003) The version-2 global precipitation climatology project (GPCP) monthly precipitation analysis (1979-present). J Hydrometeor 4(6):1147-1167. doi:10.1175/1525-7541(2003) 004 < 1147:TVGPCP $>2.0$. CO;2

Collins W, Bitz C, Blackmon M, Bonan G, Bretherton C, Carton J, Chang P, Doney S, Hack J, Henderson T, et al. (2006a) The community climate system model version 3 (CCSM3). J Clim 19(11):2122-2143. doi:10.1175/JCLI3761.1

Collins W, Rasch P, Boville B, Hack J, McCaa J, Williamson D, Briegleb B, Bitz C, Lin S, Zhang M (2006b) The formulation and atmospheric simulation of the Community Atmosphere Model version 3 (CAM3). J Clim 19(11):2144-2161. doi:10.1175/JCLI3760.1

Compo G, Whitaker J, Sardeshmukh P, Matsui N, Allan R, Yin X, Gleason B, Vose R, Rutledge G, Bessemoulin P, et al. (2011) The twentieth century reanalysis project. Quart J Roy Meteor Soc 137 (654):1-28. doi:10.1002/qj.776

Deser C, Knutti R, Solomon S, Phillips AS (2012) Communication of the role of natural variability in future North American climate. Nat Clim Chang 2(11):775-779. doi:10.1038/nclimate1562

Deser C, Phillips AS, Alexander MA, Smoliak BV (2014) Projecting North American Climate over the next 50 years: Uncertainty due to internal variability. J. Clim 27(6):2271-2296. doi:10.1175/JCLI-D-13-00451.1

Dutkiewicz S, Sokolov A, Scott J, Stone P (2005) A three-dimensional ocean-seaice-carbon cycle model and its coupling to a two-dimensional atmospheric model: uses in climate change studies. Tech. Rep. 122, MIT Joint Program on the Science and Policy of Global Change

Forest CE, Allen MR, Sokolov AP, Stone PH (2001) Constraining climate model properties using optimal fingerprint detection methods. Clim Dyn 18(3-4):277-295. doi:10.1007/s003820100175

Forest CE, Stone PH, Sokolov AP (2008) Constraining climate model parameters from observed 20th century changes. Tellus 60A(5):911-920. doi:10.1111/j.1600-0870.2008.00346.x

Hansen J, Ruedy R, Sato M, Lo K (2010) Global surface temperature change. Rev Geophys 48(4):RG4004 doi:10.1029/2010RG000345

Hasumi H, Emori S (2004) K-1 coupled gcm (MIROC) description. Tech. Rep. Center for Climate System Research, University of Tokyo, Tokyo

Hawkins E, Sutton R (2009) The potential to narrow uncertainty in regional climate predictions. Bull Am Meteorol Soc 90(8):1095-1107. doi:10.1175/2009BAMS2607.1

Hawkins E, Sutton R (2011) The potential to narrow uncertainty in projections of regional precipitation change. Clim Dyn 37(1-2):407-418. doi:10.1007/s00382-010-0810-6

Hawkins E, Sutton R (2012) Time of emergence of climate signals. Geophys Res Lett 39(1):L01,702. doi:10.1029/2011GL050087

Hurrell JW, Hack JJ, Shea D, Caron JM, Rosinski J (2008) A new sea surface temperature and sea ice boundary dataset for the Community Atmosphere Model. J Clim 21(19):5145-5153. doi:10.1175/ 2008JCLI2292.1

Kalnay E, Kanamitsu M, Kistler R, Collins W, Deaven D, Gandin L, Iredell M, Saha S, White G, Woollen J, Zhu Y, Chelliah M, Ebisuzaki W, Higgins W, Janowiak J, Mo KC, Ropelewski C, Wang J, Leetmaa A, 
Reynolds R, Jenne R, Joseph D (1996) The NCEP/NCAR 40-year reanalysis project. Bull Am Meteorol Soc 77(3):437-471. doi:10.1175/1520-0477(1996)077<0437:TNYRP > 2.0.CO;2

Kennedy A, Dong X, Xi B, Xie S, Zhang Y, Chen J (2011) A comparison of MERRA and NARR reanalyses with the DOE ARM SGP data. J Clim 24(17):4541-4557. doi:10.1175/2011JCLI3978.1

Li G, Zhang X, Zwiers F, Wen QH (2012) Quantification of uncertainty in high-resolution temperature scenarios for North America. J Clim 25(9):3373-3389. doi:10.1175/JCLI-D-11-00217.1

Mahlstein I, Knutti R, Solomon S, Portmann R (2011) Early onset of significant local warming in low latitude countries. Environ Res Lett 034(3):009. doi:10.1088/1748-9326/6/3/034009

Mahlstein I, Portmann R, Daniel J, Solomon S, Knutti R (2012) Perceptible changes in regional precipitation in a future climate. Geophys Res Lett 39(5):L05,701. doi:10.1029/2011GL050738

Marshall J, Adcroft A, Hill C, Perelman L, Heisey C (1997a) A finite-volume, incompressible navier stokes model for studies of the ocean on parallel computers. J Geophys Res 102(C3):5753-5766. doi:10.1029/96JC02775

Marshall J, Hill C, Perelman L, Adcroft A (1997b) Hydrostatic, quasi-hydrostatic, and nonhydrostatic ocean modeling. J Geophys Res 102(C3):5733-5752. doi:10.1029/96JC02776

Meehl G, Stocker T, Collins W, Friedlingstein P, Gaye A, Gregory J, Kitoh A, Knutti R, Murphy J, Noda A, Raper S, Watterson I, Weaver A, Zhao ZC (2007) Global climate projections. In: Solomon S, Qin D, Manning M, Chen Z, Marquis M, Averyt KB, Tignor M, Miller HL (eds) Climate change 2007: the physical science basis.Contribution of working group I to the fourth assessment report of the intergovernmental panel on climate change, vol 8. Cambridge University Press, Cambridge, pp 747-845

Mills D, Jones R, Carney K, St Juliana A, Ready R, Crimmins A, Martinich J, Shouse K, DeAngelo B, Monier E (2014) Quantifying and Monetizing Potential Climate Change Policy Impacts on Terrestrial Ecosystem Carbon Storage and Wildfires in the United States. Climatic Change, in press. doi:10.1007/s10584-014-1118-z

Monier E, Gao X (2014) Climate change impacts on extreme events in the United States: an uncertainty analysis. Climatic Change. doi:10.1007/s10584-013-1048-1

Monier E, Scott J, Sokolov A, Forest C, Schlosser C (2013a) An integrated assessment modelling framework for uncertainty studies in global and regional climate change: the MIT IGSM-CAM (version 1.0). Geosci Model Dev 6(6):2063-2085. doi:10.5194/gmd-6-2063-2013

Monier E, Sokolov A, Schlosser A, Scott J, Gao X (2013b) Probabilistic projections of 21st century climate change over Northern Eurasia. Environ Res Lett 8:045,008. doi:10.1088/1748-9326/8/4/045008

Otterâ O, Bentsen M, Bethke I, Kvamstø N (2009) Simulated pre-industrial climate in Bergen Climate Model (version 2): model description and large-scale circulation features. Geosci Model Dev 2:197-212. doi:10.5194/gmd-2-197-2009

Pachauri R, Reisinger A (2007) Climate change 2007 Synthesis report. contribution of working groups I, II and III to the fourth assessment report of the intergovernmental panel on climate change. Intergovernmental Panel on Climate Change

Paltsev S, Reilly J, Jacoby H, Eckaus R, McFarland J, Sarofim M, Asadoorian M, Babiker M (2005) The MIT emissions prediction and policy analysis (EPPA) model: version 4. Tech. Rep. 125, MIT Joint Program on the Science and Policy of Global Change

Paltsev S, Monier E, Scott JR, Sokolov AP, Reilly JM (2013) Integrated Economic and Climate Projections for Impact Assessment. Climatic Change. doi:10.1007/s10584-013-0892-3

Randall DA, WR A, Bony S, Colman R, Fichefet T, Fyfe J, Kattsov V, Pitman A, Shukla J, Srinivasan J, Stouffer RJ, Sumi A, Taylor KE (2007) Climate models and their evaluation. In: Solomon S, Qin D, Manning M, Chen Z, Marquis M, Averyt KB, Tignor M, Miller HL (eds) Climate Change 2007: The physical science basis. Contribution of working group I to the fourth assessment report of the intergovernmental panel on climate change, vol 10. Cambridge University Press, Cambridge, pp 589-662

Reilly J, Paltsev S, Strzepek K, Selin NE, Cai Y, Nam KM, Monier E, Dutkiewicz S, Scott J, Webster M, Sokolov A (2013) Valuing climate impacts in integrated assessment models: the MIT IGSM. Climatic Change 117(3): 561-573. doi:10.1007/s10584-012-0635-x

Rienecker M, Suarez M, Gelaro R, Todling R, Bacmeister J, Liu E, Bosilovich M, Schubert S, Takacs L, Kim G, et al. (2011) MERRA: NASA's modern-era retrospective analysis for research and applications. J Clim 24(14):3624-3648. doi:10.1175/JCLI-D-11-00015.1

Schlosser CA, Gao X, Strzepek K, Sokolov A, Forest C, Awadalla S, Farmer W (2013) Quantifying the 484 likelihood of regional climate change: a hybridized approach. J Clim 26(10):3394-3414. doi:10.1175/JCLI-D-11-00730.1

Sokolov A, Monier E (2012) Changing the climate sensitivity of an atmospheric general circulation model through cloud radiative adjustment. J Clim 25(19):6567-6584. doi:10.1175/JCLI-D-11-00590.1 
Sokolov A, Schlosser C, Dutkiewicz S, Paltsev S, Kicklighter D, Jacoby H, Prinn R, Forest C, Reilly J, Wang C, et al. (2005) MIT integrated global system model (IGSM) version 2: model description and baseline evaluation. Tech. Rep. 124, MIT Joint Program on the Science and Policy of Global Change

Sokolov A, Stone P, Forest C, Prinn R, Sarofim M, Webster M, Paltsev S, Schlosser C, Kicklighter D, Dutkiewicz S, et al. (2009) Probabilistic forecast for twenty-first-century climate based on uncertainties in emissions (without policy) and climate parameters. J Clim 22(19):5175-5204. doi:10.1175/2009JCLI2863.1

Thompson D, Solomon S (2002) Interpretation of recent Southern Hemisphere climate change. Science 296(5569):895-899. doi:10.1126/science. 1069270

Waldhoff S, Martinich J, Sarofim M, DeAngelo B, McFarland J, Jantarasami L, Shouse K, Crimmins A, Li J (2013) Overview of the Special Issue: A multi-model framework to achieve consistent evaluation of climate change impacts in the United States. Climatic Change. (submitted, this issue)

Webster M, Sokolov AP, Reilly JM, Forest CE, Paltsev S, Schlosser CA, Wang C, Kicklighter D, Sarofim M, Melillo J, Prinn RG, Jacoby HD (2012) Analysis of climate policy targets under uncertainty. Clim Chang 112(3-4):569-583. doi:10.1007/s10584-011-0260-0 